\title{
No relationship between thymidine phosphorylase (TP, PD-ECGF) expression and hypoxia in carcinoma of the cervix
}

\author{
P Kabuubi', JA Loncaster', SE Davidson', RD Hunter', C Kobylecki', IJ Stratford ${ }^{3}$ and CML West ${ }^{*, 1}$ \\ 'Academic Department of Radiation Oncology, The University of Manchester, Christie Hospital NHS Trust, Manchester M20 4BX, UK; ${ }^{2}$ Department of \\ Clinical Oncology, Christie Hospital NHS Trust, Manchester M20 4BX, UK; ${ }^{3}$ Experimental Oncology Group, School of Pharmacy and Pharmaceutical \\ Sciences, The University of Manchester, Oxford Road, Manchester MI 3 9PL, UK
}

\begin{abstract}
The expression of hypoxia-regulated genes promotes an aggressive tumour phenotype and is associated with an adverse cancer treatment outcome. Thymidine phosphorylase (TP) levels increase under hypoxia, but the protein has not been studied in association with hypoxia in human tumours. An investigation was made, therefore, of the relationship of tumour TP with hypoxia, the expression of other hypoxia-associated markers and clinical outcome. This retrospective study was carried out in patients with locally advanced cervical carcinoma who underwent radiotherapy. Protein expression was evaluated with immunohistochemistry. Hypoxia was measured using microelectrodes and the level of pimonidazole binding. There was no relationship of TP expression with tumour $\mathrm{PO}_{2}$ $(r=-0.091, P=0.59, n=87)$ or pimonidazole binding $(r=0.13, P=0.45, n=38)$. There was no relationship between TP and HIF$\mid \alpha$, but there was a weak borderline significant relationship with HIF-2 $\alpha$ expression. There were weak but significant correlations of TP with the expression of VEGF, CA IX and Glut-I. In II 9 patients, the presence of TP expression predicted for disease-specific $(P=0.032)$ and metastasis-free $(P=0.050)$ survival. The results suggest that TP is not a surrogate marker of hypoxia, but is linked to the expression of hypoxia-associated genes and has weak prognostic power.
\end{abstract}

British Journal of Cancer (2006) 94, I I5-120. doi:I0.1038/sj.bjc.6602882 www.bjcancer.com

Published online 29 November 2005

(c) 2006 Cancer Research UK

Keywords: thymidine phosphorylase; hypoxia; hypoxia-inducible factor; cervix

Thymidine phosphorylase (TP), previously called PD-ECGF, is a $110 \mathrm{kDa}$ protein homodimer which was originally isolated from platelets showing endothelial mitogenic activity (Miyazono et al, 1987). It was subsequently identified in other tissues including placenta, macrophages, lung, liver, spleen and peripheral lymphocytes (Yoshimura et al, 1990). Levels of the protein are elevated in solid tumours (Yoshimura et al, 1990; Takebayashi et al, 1996, 1999), rheumatoid arthritis synovium (Asai et al, 1993) and psoriatic lesions (Creamer et al, 1997).

Little is known about the regulation of TP expression, although certain cytokines are implicated in increasing its activity, including interleukin-1, tumour necrosis factor- $\alpha$, fibroblast growth factor- $\beta$ and interferon- $\alpha$ (Tevaearai et al, 1992; Eda et al, 1993; de Bruin et al, 2004). In vitro studies have shown that TP expression is also induced by hypoxia. Griffiths et al (1997)found TP expression in MDA 231 cells increased six-fold following $16 \mathrm{~h}$ growth in $0.3 \%$ oxygen). More recently, Abbas et al (2004) showed TP expression increased two-fold under hypoxia in human endometrial stromal cells. Cobalt stimulation increases TP levels, suggesting that its expression might be regulated by hypoxia-enhancer elements, that is, hypoxia-inducible factor (HIF) (Griffiths et al, 1997). Indeed, Sivridis et al (2002b) showed that HIF-2 $\alpha$ overexpression was

*Correspondence: Dr CML West;

E-mail: catharine.west@manchester.ac.uk

Received 16 August 2005; accepted 27 October 2005; published online 29 November 2005 linked to TP expression in human endometrial adenocarcinomas. Interestingly, in the TP-overexpressing cell line RT112-TP, TP augmented the hypoxic induction of HIF-1 $\alpha$ (Brown et al, 2005).

Thymidine phosphorylase has angiogenic properties (Moghaddam et al, 1995) which are dependent on its enzymatic activity (Miyazono et al, 1987; Miyadera et al, 1995). A relationship between TP expression and microvessel density, a histological measure of angiogenesis, has been reported in several solid tumours such as breast (Toi et al, 1995a), ovarian (Reynolds et al, 1994) renal (Imazano et al, 1997), and gastric (Takebayashi et al, 1996). In experimental models, TP overexpression increased tumour cell invasion (Ueda et al, 2001) and tumorigenicity (Griffiths and Stratford 1998; Brown et al, 2005). In man, high tumour expression of TP generally correlates with a poor prognosis in various solid malignancies (Takebayashi et al, 1996; Ikeda et al, 1999) including cervix cancer (Fujimoto et al, 1999; Hata et al, 1999; Ueda et al, 1999). However, this finding is not universal, as one study in cervix cancer showed that high tumour TP positivity was associated with a good prognosis (Oka et al, 2003). Of interest, high stromal TP expression correlated with a favourable prognosis in patients with colorectal carcinoma not receiving 5-FU based chemotherapy, which led the authors to suggest that TP produced by tumour cells and stromal macrophages may exert different roles (Yasuno et al, 2005).

The relationship between TP and VEGF is also of interest. There is evidence that VEGF may act downstream of TP (Brown et al, 2000), and that hypoxia augments the effect of TP on VEGF 
(Brown et al, 2005). The two proteins coexpress in breast carcinomas (Toi et al, 1995b) and this coexpression was the most potent angiogenic phenotype in endometrial carcinoma (Sivridis et al, 2002a). In contrast, an inverse relationship between TP and VEGF expression was found in cervical carcinomas (Tokumo et al, 1998 ) and their angiogenic activity appears highest when expressed relatively alone in human colon cancers (Takahashi et al, 1996).

In view of the uncertainty over the role of TP, the aims of this study were to examine the relationship of tumour TP expression with hypoxia, the expression of hypoxia-associated proteins and prognosis in patients with carcinoma of the cervix.

\section{MATERIALS AND METHODS}

\section{Patients}

Two series of patients were studied. Local ethical approval was obtained and full prior written consent was gained from all the patients. The first series of patients comprised 119 patients with locally advanced carcinoma of the uterine cervix treated with radical radiotherapy at the Christie Hospital NHS Trust between 1987 and 1993. Median follow-up was 60 months (range 27-115 months). Random cervical punch biopsies were taken prior to radical radiotherapy. Treatment was given according to standard techniques and dosages of the Manchester School (West et al, 1993). On completion of treatment they were reviewed following a standard protocol (a minimum of three monthly for the first year, four monthly for the second and third years, and six monthly in the fourth and fifth years). The sites of any disease relapse were identified clinically, radiologically, and histologically where appropriate. The recurrences were then classified as being either local (i.e. within the radiotherapy field) or metastatic.

The second series comprised a more recently treated group of 87 patients with locally advanced carcinoma of the cervix seen between May 1996 and December 1999. Tumour oxygenation data were obtained using an Eppendorf $\mathrm{pO}_{2}$ histograph as described elsewhere (Cooper et al, 1999).

\section{Pimonidazole binding}

The method used for administration of pimonidazole to patients (Hypoxyprobe-1; NPI Inc. Belmont, MA, USA), taking tumour biopsies and staining have been described elsewhere (Nordsmark et al, 2001). Patients were biopsied $12-20 \mathrm{~h}$ after receiving pimonidazole. A semiquantitative scoring system was used to quantify pimonidazole binding as described elsewhere (Hutchison et al, 2004).

\section{TP expression}

All staining was carried out on pretreatment biopsies. Immunohistochemical detection of TP was carried out using an immunoperoxidase method, as described elsewhere (Shimaoka et al, 2000). Formalin-fixed samples were embedded in paraffin and cut into $4 \mu \mathrm{m}$ thick sections. These were then deparaffinized with xylene, dehydrated using $100 \%$ ethanol, and washed with methanol. Endogenous peroxidase was blocked by immersion in $0.3 \% \mathrm{H}_{2} \mathrm{O}_{2}$ in methanol for $30 \mathrm{~min}$ at room temperature (RT). The blocked sections were then washed in methanol, running water and three 5 min washes in TBS ( $\mathrm{pH} 7.6$ ). Slides were dried and 10\% normal rabbit serum (DAKO XO902) was applied for $10 \mathrm{~min}$ at RT. The sections were incubated overnight at $4^{\circ} \mathrm{C}$ with a $1: 30$ dilution of primary mouse monoclonal antibody (gift from Adrian Harris). After washing, the slides were incubated for $30 \mathrm{~min}$ at RT with 1:400 rabbit anti-mouse biotinylated secondary antibody (DAKO EO413). The sections were then washed and incubated for $30 \mathrm{~min}$ at RT with streptavidin-biotin complex/horseradish peroxidase (sABC/HRP) in TBS. Following a further wash, the slides were incubated for $5 \mathrm{~min}$ with $0.5 \mathrm{mg} \mathrm{ml}^{-1}$ diaminobenzidine (DAB) in $0.03 \% \mathrm{H}_{2} \mathrm{O}_{2}$. The sections were washed in distilled water and counterstained with haematoxylin before dehydrating and mounting.

The extent and distribution of TP staining was evaluated under low magnification, without the observer's knowledge of outcome data or oxygen measurements. The level of expression in the tumour cells was evaluated using a semiquantitative scoring system: 0 for absence of immunostaining, 1 for light staining, 2 for moderate staining, and 3 for heavy staining. Any staining of the tumour stroma was ignored in this assessment. All scoring was performed in a double-blind manner by two independent investigators.

\section{MVD, VEGF, HIF, CA IX, Glut-1}

The staining and scoring methods for MVD (Cooper et al, 1998), VEGF (Loncaster et al, 2000), HIF- $1 \alpha$ (Hutchison et al, 2004), HIF$2 \alpha$ (Beasley et al, 2002), CA IX (Loncaster et al, 2001) and Glut-1 (Airley et al, 2001) have been described elsewhere Only tumour nuclear HIF- $1 \alpha$ was scored as described elsewhere (Aebersold $e t$ al, 2001). All scoring was performed in a double-blind manner by two independent investigators.

\section{Statistical analysis}

Correlations between measurements were examined using Spearman's rank correlation. The distribution of TP score in relation to patient and tumour characteristics was investigated using Fisher's exact test. Survival was analysed using the Kaplan-Meier method and prognostic factors were assessed using log-rank analysis. Univariate and bivariate analyses were made of overall, metastasisfree and recurrence-free survival. Patients were stratified by their TP expression score as well as other putative prognostic factors (stage, age, differentiation). A stepwise multivariate Cox regression analysis was performed to further test the independence of TP from other parameters.

\section{RESULTS}

\section{TP expression}

Positive TP expression was seen in 92\% (188/206) of the tumours. The expression was generally homogeneous within epithelial cells, and was predominantly cytoplasmic, with some nuclear staining. There was some degree of stromal TP expression thought to be owing to macrophage infiltration, but this was small relative to the tumour cytoplasmic staining. Higher levels of TP expression were seen adjacent to areas of necrosis, but no pattern in relation to tumour vasculature was observed.

\section{Scoring reproducibility}

Intra-observer variation in scoring TP expression was tested by rescoring all the tumour sections. There was a significant correlation between the two scores $(r=0.92, P<0.001)$. Inter-observer variation was tested by a second observer scoring all the same sections. Again, there was significant correlation between the scores $(r=0.88, P=0.001)$. Assessment of batch to batch variation showed sections stained on multiple occasions scored identically.

\section{TP expression and tumour oxygen measurements}

In a series of 87 tumours, a median of four oxygen electrode tracks (range 1-7) was made per tumour, resulting in a median of 128 oxygen measurements (range $32-192$ ). The median $\mathrm{pO}_{2}$ level was $4 \mathrm{mmHg}$ (range $0-45 \mathrm{mmHg}$ ), and the median HP5 (percentage of values less than $5 \mathrm{mmHg}$ ) was $52 \%$ (range $0-96 \%$ ). There was no 
relationship between TP expression and the Eppendorf measurements of tumour oxygenation. The correlations with median $\mathrm{pO}_{2}$ and HP5 were $r=-0.091, P=0.59$ and $r=-0.014, P=0.93$, respectively. There was no correlation between TP expression and pimonidazole staining $(r=0.13, P=0.45, n=38)$.

\section{Relationship with angiogenesis and hypoxia-inducible markers}

There was no relationship between TP expression and MVD $(r=-0.15, P=0.10, n=120)$. There was a weak positive relationship between TP and VEGF expression $(r=0.36, P=0.001, n=89)$. Expressions of both proteins were independent of disease stage and there was no significant difference between the distributions of the scores with stage for the two proteins. There was no significant relationship between TP and HIF- $1 \alpha$ expression $(r=-0.062$, $P=0.68, n=46)$. There were weak but significant positive relationships between TP expression and CA-IX $(r=0.22$, $P=0.015, n=122)$ and Glut-1 $(r=0.31, P=0.002, n=96)$. HIF$2 \alpha$ showed a weak borderline significant relationship with TP expression $(r=0.34, P=0.09, n=26)$.

\section{Correlation with outcome}

Table 1 summarises the distribution of tumour TP expression in relation to patient and tumour characteristics in 119 patients. Using Fisher's exact test, TP expression was independent of tumour stage and differentiation. Higher levels of expression were seen in tumour from younger patients.

Figure 1 illustrates the relationship between TP expression and treatment outcome. The level of expression was a significant prognostic factor for metastasis-free survival $(P=0.031)$ and a borderline significant prognostic factor for disease-specific survival $(P=0.067)$. There was no relationship with local control $(P=0.23)$. The analyses were repeated stratifying patients by the presence or absence of immunostaining (Figure 2). The prognostic significance of TP expression was similar for both disease-specific $(P=0.032)$ and metastasis-free $(P=0.050)$ survival. The sensitivity of TP in predicting a poor outcome was $96 \%$ for both diseasespecific and metastasis-free survival. However, the respective specificities were only 16 and $14 \%$. The respective positive predictive values of tumour TP positivity were 50 and $44 \%$. Table 2 summarises the results of univariate log-rank analyses of outcome following radiotherapy. Tumour stage was the strongest prognostic factor, followed by TP expression. Bivariate analyses were carried out examining the prognostic significance of TP expression after allowing for disease stage, tumour grade and patient age (Table 3 ).

Table I Distribution of patients according to TP expression

\begin{tabular}{|c|c|c|c|c|c|c|}
\hline \multirow[b]{2}{*}{ Parameter } & \multirow[b]{2}{*}{$\mathbf{N}$} & \multicolumn{4}{|c|}{ TP score } & \multirow[b]{2}{*}{$P^{\mathbf{a}}$} \\
\hline & & 0 & I & 2 & 3 & \\
\hline \multicolumn{7}{|l|}{ Stage } \\
\hline I & 32 & 6 & 10 & | | & 5 & \multirow[t]{4}{*}{0.13} \\
\hline$\|$ & 34 & 2 & 9 & 9 & 14 & \\
\hline III & 45 & 4 & 14 & 18 & 9 & \\
\hline IV & 8 & 0 & 5 & I & 2 & \\
\hline \multicolumn{7}{|l|}{ Age } \\
\hline$<52$ years & 59 & 9 & 18 & | | & 21 & \multirow[t]{2}{*}{0.002} \\
\hline$>52$ years & 60 & 3 & 20 & 28 & 9 & \\
\hline \multicolumn{7}{|l|}{ Differentiation } \\
\hline Well & 23 & I & 7 & 8 & 7 & \multirow[t]{3}{*}{0.97} \\
\hline Moderate & 74 & 8 & 24 & 24 & 18 & \\
\hline Poor & 16 & | & 6 & 5 & 4 & \\
\hline
\end{tabular}

${ }^{a} P=$ statistical significance using Fisher's exact test.
TP expression remained a weak predictor of disease-free and metastasis-free survival after allowing for disease stage, patient age and tumour grade. Adding the scores for TP and VEGF expression did not improve the prognostic ability over VEGF expression alone for disease-specific and metastasis-free survival $(P=0.0057$ and $P=0.0024$, respectively). However, the combined score was better at predicting local control than either VEGF or TP alone $(P=0.029)$.

\section{DISCUSSION}

The immunohistochemical detection of the intensity of TP expression has been shown to correlate with TP levels as determined by immunoassay (Fujimoto et al, 1999). The scoring
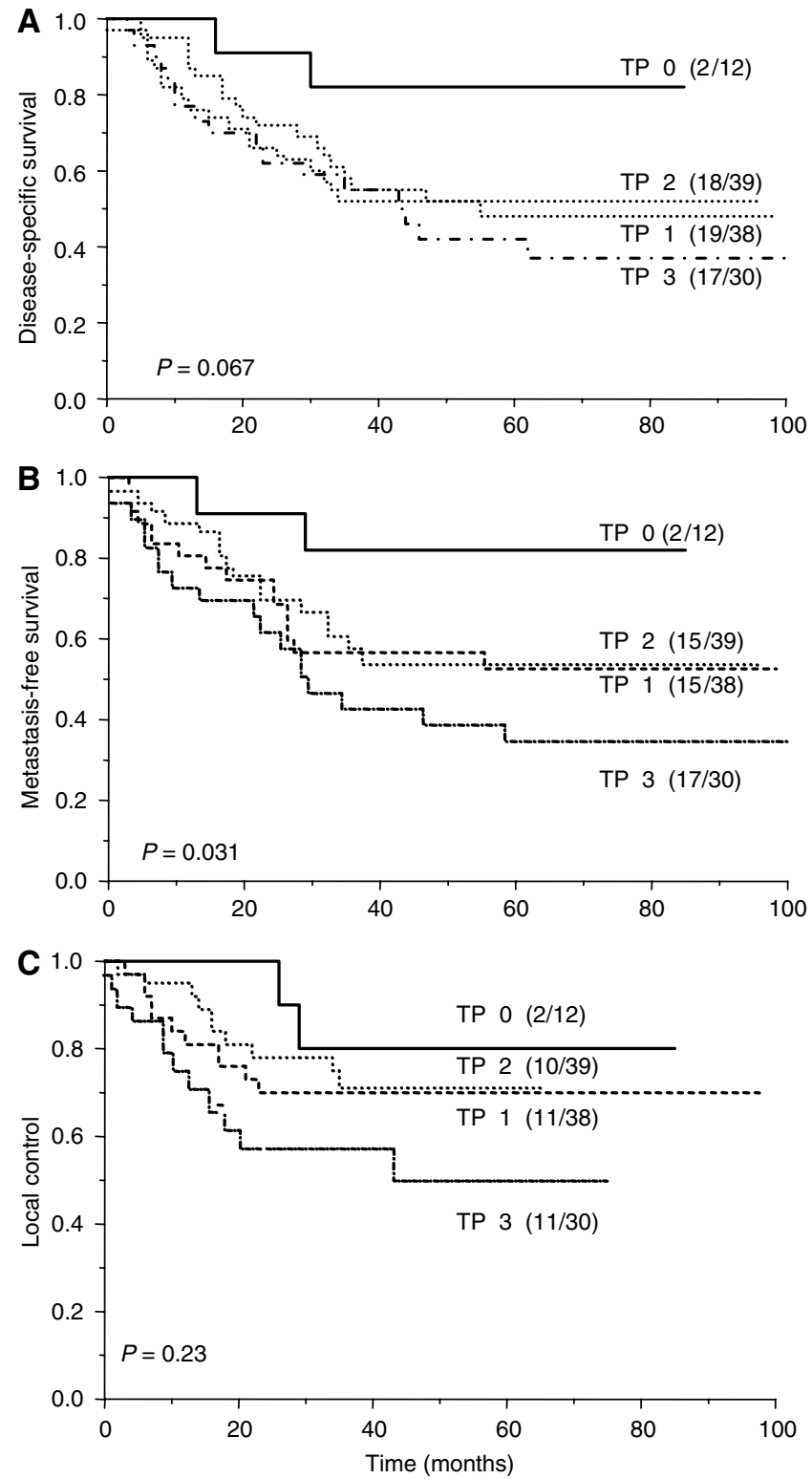

Figure I Disease-specific survival $(\mathbf{A})$, metastasis-free survival $(\mathbf{B})$ and local control (C), in relation to TP expression in 119 cervical cancer patients who received radical radiotherapy. Patients were stratified according to the intensity of TP expression $(0=$ no staining, I = light staining, $2=$ moderate staining and $3=$ heavy staining). The numbers of events and patients in each arm are indicated. 


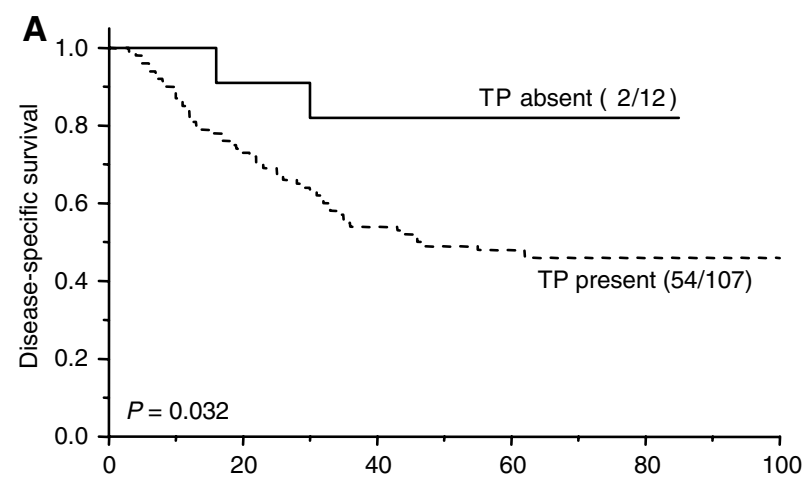

Table 2 Univariate log-rank analysis of putative prognostic factors for outcome following radiotherapy for carcinoma of the cervix

\begin{tabular}{lcccc}
\hline Parameter & $\boldsymbol{n}$ & $\begin{array}{c}\text { Disease-specific } \\
\text { survival }\end{array}$ & $\begin{array}{c}\text { Metastasis- } \\
\text { free survival }\end{array}$ & $\begin{array}{c}\text { Local } \\
\text { control }\end{array}$ \\
\hline Stage & 119 & $<0.001$ & 0.005 & 0.11 \\
Age & 119 & 0.65 & 0.12 & 0.043 \\
Differentiation $^{\mathrm{a}}$ & 113 & 0.81 & 0.69 & 0.25 \\
TP expression $^{\mathrm{a}}$ & 119 & 0.067 & 0.031 & 0.23 \\
\hline
\end{tabular}

${ }^{a}$ Analysed using univariate Cox test for trend The $P$-value for each factor is given.

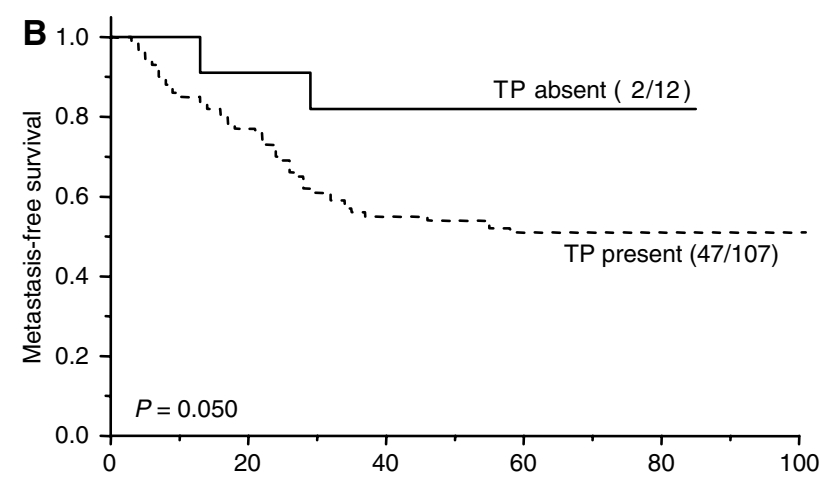

Table 3 Bivariate stratified log-rank analyses showing the significance of the level of TP expression as a prognostic factor after allowing for the listed parameters

\begin{tabular}{lcccc}
\hline Parameter & $\boldsymbol{n}$ & $\begin{array}{c}\text { Disease-specific } \\
\text { survival }\end{array}$ & $\begin{array}{c}\text { Metastasis- } \\
\text { free survival }\end{array}$ & $\begin{array}{c}\text { Local } \\
\text { control }\end{array}$ \\
\hline Stage & 119 & 0.091 & 0.049 & 0.21 \\
Age & 119 & 0.19 & 0.053 & 0.25 \\
Differentiation & 113 & 0.21 & 0.078 & 0.30 \\
\hline
\end{tabular}

The $P$-value for each factor is given.

relationship between $\mathrm{TP}$ and hypoxia might relate to its role in stimulating angiogenesis. In comparison with wild-type cells, xenografted TP-overexpressing breast cancer cells were shown to be better oxygenated (measured using the comet assay). The authors suggested the finding was consistent with the TPoverexpressing tumours having an increased and functionally more competent vasculature (Griffiths and Stratford, 1998). Clearly, the relationships between hypoxia, angiogenesis and TP are unlikely to be simple. How the relationships might change during tumorigenesis, that is, from pre-malignant to early stage to advanced disease, remains to be explored.

Although TP is upregulated under hypoxia, we found no relationship between the expression of TP and HIF- $1 \alpha$ in cervix tumours. As for TP, HIF- $1 \alpha$ protein levels can be raised in tumours due to stimuli other than hypoxia: activation of oncogenes HER2 (Laughner et al, 2001), v-src (Jiang et al, 1997) and H-ras (Chen et al, 2001); loss of tumour suppressor gene function such as PTEN (Zundel et al, 2000) and signalling abnormalities such as MAPK (Richard et al, 1999). The relationship between TP and HIF has not been studied widely. While we found no relationship between TP and HIF- $1 \alpha$ expression there was a borderline correlation with HIF- $2 \alpha$. This observation is consistent with a finding in human endometrial cancers of an association between tumour expression of TP and HIF- $2 \alpha$ but not HIF- $1 \alpha$ (Sivridis et al, 2002b). Recent evidence showed that whereas some genes are upregulated by HIF$1 \alpha$ and HIF- $2 \alpha$, others are preferentially activated by one or the other factor (Wang et al, 2005). It might be, therefore, that TP is preferentially induced by HIF- $2 \alpha$. Of interest is the observation that TP increased the hypoxic expression of HIF- $1 \alpha$ in an orthoptic xenograft model of bladder cancer (Brown et al, 2005). This finding suggests that TP can be added to the long list of factors that promote HIF activation.

Consistent with the suggestion that TP promotes HIF- $\alpha$ expression, we found weak relationships between tumour TP expression and the expression of proteins upregulated by HIF (VEGF, CAIX and Glut-1). These results are also consistent with published evidence showing either a correlation or coexpression of TP with VEGF (Fujimoto et al, 1998; O'Byrne et al, 2000; van Triest et al, 2000) and CA-IX (Giatromanolaki et al, 2001). Studies have also shown that TP may stimulate VEGF expression. Increasing TP enzymatic activity induces oxidative stress which has been shown to upregulate various cytokines including VEGF (Brown et al, 
2000). Furthermore, increased TP activity augments VEGF expression under hypoxic conditions in vivo (Brown et al, 2005). Our data support this relationship. TP and its enzymatic products have been shown to be angiogenic in various models (Moghaddam et al, 1995; Jones et al, 2002). These effects may be synergistic with or mediated by VEGF.

This study found TP expression to be a weak prognostic indicator in locally advanced carcinoma of the cervix. As we showed previously for VEGF (Loncaster et al, 2000), TP significantly predicted for metastasis-free survival but not local control. This is consistent with its role as a promoter of tumour angiogenesis rather than a role in hypoxia-associated radioresistance.

The exact role of TP in tumorigenesis and angiogenesis remains unclear. Studies have shown that the use of TP inhibitors in TPoverexpressing xenografted cell lines reduced angiogenesis and increased apoptosis (Matsushita et al, 1999). These results have not yet been developed into clinical trials. Nevertheless, owing to tumour-specific activating and deactivating mutations, the efficacy of TP inhibitors might vary not only between individual tumours but also between different types of tumours. Emphasis should be placed on elucidating the exact relationship of TP with other angiogenic factors, HIF, signalling abnormalities, oncogene activation and loss of tumour suppressor gene function. Such information should prove useful for the successful introduction of TP inhibition strategies into clinical practice.

\section{ACKNOWLEDGEMENTS}

This work was supported by Cancer Research UK, and the National Translational Cancer Research Network and Medical Research Council of the UK. We thank Dr Jo Cresswell for scientific administration.

\section{REFERENCES}

Abbas MM, Evans JJ, Sykes PH, Benny PS (2004) Modulation of vascular endothelial growth factor and thymidine phosphorylase in normal human endometrial stromal cells. Fertil Steril 82(Suppl 3): 1048-1053

Aebersold DM, Burri P, Beer KT, Laissue J, Djonov V, Greiner RH, Semenza GL (2001) Expression of hypoxia-inducible factor-1alpha: a novel predictive and prognostic parameter in the radiotherapy of oropharyngeal cancer. Cancer Res 61: 2911-2916

Airley R, Loncaster J, Davidson S, Bromley M, Roberts S, Patterson A, Hunter R, Stratford I, West C (2001) Glucose transporter glut-1 expression correlates with tumor hypoxia and predicts metastasis-free survival in advanced carcinoma of the cervix. Clin Cancer Res 7: 928-934

Asai K, Hirano T, Matsukawa K, Kusada J, Takeuchi M, Otsuka T, Matsui N, Kato T (1993) High concentrations of immunoreactive gliostatin/ platelet-derived endothelial cell growth factor in synovial fluid and serum of rheumatoid arthritis. Clin Chim Acta 218: 1-4

Beasley NJ, Leek R, Alam M, Turley H, Cox GJ, Gatter K, Millard P, Fuggle S, Harris AL (2002) Hypoxia-inducible factors HIF-1alpha and HIF-2alpha in head and neck cancer: relationship to tumor biology and treatment outcome in surgically resected patients. Cancer Res 62: $2493-2497$

Brown NS, Jones A, Fujiyama C, Harris AL, Bicknell R (2000) Thymidine phosphorylase induces carcinoma cell oxidative stress and promotes secretion of angiogenic factors. Cancer Res 60: 6298-6302

Brown NS, Streeter EH, Jones A, Harris AL, Bicknell R (2005) Cooperative stimulation of vascular endothelial growth factor expression by hypoxia and reactive oxygen species: the effect of targeting vascular endothelial growth factor and oxidative stress in an orthotopic xenograft model of bladder carcinoma. Br J Cancer 92: 1696-1701

Chen C, Pore N, Behrooz A, Ismail-Beigi F, Maity A (2001) Regulation of glut1 mRNA by hypoxia-inducible factor-1. Interaction between $\mathrm{H}$-ras and hypoxia. J Biol Chem 276: 9519-9525

Cooper RA, West CM, Logue JP, Davidson SE, Miller A, Roberts S, Statford IJ, Honess DJ, Hunter RD (1999) Changes in oxygenation during radiotherapy in carcinoma of the cervix. Int J Radiat Oncol Biol Phys 45: $119-126$

Cooper RA, Wilks DP, Logue JP, Davidson SE, Hunter RD, Roberts SA, West CM (1998) High tumor angiogenesis is associated with poorer survival in carcinoma of the cervix treated with radiotherapy. Clin Cancer Res 4: 2795-2800

Creamer D, Jaggar R, Allen M, Bicknell R, Barker J (1997) Overexpression of the angiogenic factor platelet-derived endothelial cell growth factor/ thymidine phosphorylase in psoriatic epidermis. $\mathrm{Br} J$ Dermatol 137: $851-855$

de Bruin M, Smid K, van der Ent MA, Fukushima M, Pinedo HM, Peters GJ (2004) Upregulation of platelet derived endothelial cell growth factor/ thymidine phosphorylase by interferon alpha. Nucleosides Nucleotides Nucleic Acids 23: $1367-1370$

Eda H, Fujimoto K, Watanabe S, Ura M, Hino A, Tanaka Y, Wada K, Ishitsuka H (1993) Cytokines induce thymidine phosphorylase expression in tumor cells and make them more susceptible to $5^{\prime}$-deoxy-5fluorouridine. Cancer Chemother Pharmacol 32: 333-338
Fujimoto J, Sakaguchi H, Hirose R, Ichigo S, Tamaya T (1999) Expression of platelet-derived endothelial cell growth factor (PD-ECGF) and its mRNA in uterine cervical cancers. Br J Cancer 79: 1249-1254

Fujimoto K, Hosotani R, Wada M, Lee JU, Koshiba T, Miyamoto Y, Tsuji S, Nakajima S, Doi R, Imamura M (1998) Expression of two angiogenic factors, vascular endothelial growth factor and platelet-derived endothelial cell growth factor in human pancreatic cancer, and its relationship to angiogenesis. Eur J Cancer 34: 1439- 1447

Giatromanolaki A, Koukourakis MI, Sivridis E, Turley H, Talks K, Pezzella F, Gatter KC, Harris AL (2001) Relation of hypoxia inducible factor 1 alpha and 2 alpha in operable non-small cell lung cancer to angiogenic/ molecular profile of tumours and survival. Br J Cancer 85: 881-890

Griffiths L, Dachs GU, Bicknell R, Harris AL, Stratford IJ (1997) The influence of oxygen tension and $\mathrm{pH}$ on the expression of platelet-derived endothelial cell growth factor/thymidine phosphorylase in human breast tumor cells grown in vitro and in vivo. Cancer Res 57: 570-572

Griffiths L, Stratford IJ (1998) The influence of elevated levels of plateletderived endothelial cell growth factor/thymidine phosphorylase on tumourigenicity, tumour growth, and oxygenation. Int J Radiat Oncol Biol Phys 42: $877-883$

Hata K, Takebayashi Y, Iida K, Fujiwaki R, Fukumoto M, Miyazaki K (1999) Expression of thymidine phosphorylase in human cervical cancer. Anticancer Res 19: 709-716

Hutchison GJ, Valentine HR, Loncaster JA, Davidson SE, Hunter RD, Roberts SA, Harris AL, Stratford IJ, Price PM, West CM (2004) Hypoxiainducible factor 1alpha expression as an intrinsic marker of hypoxia: correlation with tumor oxygen, pimonidazole measurements, and outcome in locally advanced carcinoma of the cervix. Clin Cancer Res 10: $8405-8412$

Ikeda N, Adachi M, Taki T, Huang C, Hashida H, Takabayashi A, Sho M, Nakajima Y, Kanehiro H, Hisanaga M, Nakano H, Miyake M (1999) Prognostic significance of angiogenesis in human pancreatic cancer. $\mathrm{Br} \mathrm{J}$ Cancer 79: $1553-1563$

Imazano Y, Takebayashi Y, Nishiyama K, Akiba S, Miyadera K, Yamada Y, Akiyama S, Ohi Y (1997) Correlation between thymidine phosphorylase expression and prognosis in human renal cell carcinoma. J Clin Oncol 15: $2570-2578$

Jiang BH, Agani F, Passaniti A, Semenza GL (1997) V-SRC induces expression of hypoxia-inducible factor 1 (HIF-1) and transcription of genes encoding vascular endothelial growth factor and enolase 1: involvement of HIF-1 in tumor progression. Cancer Res 57: 5328-5335

Jones A, Fujiyama C, Turner K, Cranston D, Williams K, Stratford I, Bicknell R, Harris AL (2002) Role of thymidine phosphorylase in an in vitro model of human bladder cancer invasion. J Urol 167: $1482-1486$

Kojima H, Shijubo N, Abe S (2002) Thymidine phosphorylase and vascular endothelial growth factor in patients with Stage I lung adenocarcinoma. Cancer 94: 1083 - 1093

Koukourakis MI, Giatromanolaki A, O’Byrne KJ, Cox J, Krammer B, Gatter KC, Harris AL (1999) bcl-2 and c-erbB-2 proteins are involved in the regulation of VEGF and of thymidine phosphorylase angiogenic activity in non-small-cell lung cancer. Clin Exp Metastasis 17: 545-554 
Laughner E, Taghavi P, Chiles K, Mahon PC, Semenza GL (2001) HER2 (neu) signaling increases the rate of hypoxia-inducible factor 1alpha (HIF-1alpha) synthesis: novel mechanism for HIF-1-mediated vascular endothelial growth factor expression. Mol Cell Biol 21: 3995-4004

Loncaster JA, Cooper RA, Logue JP, Davidson SE, Hunter RD, West CM (2000) Vascular endothelial growth factor (VEGF) expression is a prognostic factor for radiotherapy outcome in advanced carcinoma of the cervix. Br J Cancer 83: 620-625

Loncaster JA, Harris AL, Davidson SE, Logue JP, Hunter RD, Wycoff CC, Pastorek J, Ratcliffe PJ, Stratford IJ, West CM (2001) Carbonic anhydrase (CA IX) expression, a potential new intrinsic marker of hypoxia: correlations with tumor oxygen measurements and prognosis in locally advanced carcinoma of the cervix. Cancer Res 61: 6394-6399

Matsushita S, Nitanda T, Furukawa T, Sumizawa T, Tani A, Nishimoto K, Akiba S, Miyadera K, Fukushima M, Yamada Y, Yoshida H, Kanzaki T, Akiyama S (1999) The effect of a thymidine phosphorylase inhibitor on angiogenesis and apoptosis in tumors. Cancer Res 59: 1911- 1916

Miyadera K, Dohmae N, Takio K, Sumizawa T, Haraguchi M, Furukawa T, Yamada Y, Akiyama S (1995) Structural characterization of thymidine phosphorylase purified from human placenta. Biochem Biophys Res Commun 212: $1040-1045$

Miyazono K, Okabe T, Urabe A, Takaku F, Heldin CH (1987) Purification and properties of an endothelial cell growth factor from human platelets. J Biol Chem 262: 4098-4103

Moghaddam A, Zhang HT, Fan TP, Hu DE, Lees VC, Turley H, Fox SB, Gatter KC, Harris AL, Bicknell R (1995) Thymidine phosphorylase is angiogenic and promotes tumor growth. Proc Natl Acad Sci USA 92: $998-1002$

Nordsmark M, Loncaster J, Chou SC, Havsteen H, Lindegaard JC, Davidson SE, Varia M, West C, Hunter R, Overgaard J, Raleigh JA (2001) Invasive oxygen measurements and pimonidazole labeling in human cervix carcinoma. Int J Radiat Oncol Biol Phys 49: 581-586

O'Byrne KJ, Koukourakis MI, Giatromanolaki A, Cox G, Turley H, Steward WP, Gatter K, Harris AL (2000) Vascular endothelial growth factor, platelet-derived endothelial cell growth factor and angiogenesis in nonsmall-cell lung cancer. Br J Cancer 82: 1427-1432

Oka K, Suzuki Y, Iida H, Nakano T (2003) Pd-ECGF positivity correlates with better survival, while iNOS has no predictive value for cervical carcinomas treated with radiotherapy. Int J Radiat Oncol Biol Phys 57: $217-221$

Reynolds K, Farzaneh F, Collins WP, Campbell S, Bourne TH, Lawton F, Moghaddam A, Harris AL, Bicknell R (1994) Association of ovarian malignancy with expression of platelet-derived endothelial cell growth factor. I Natl Cancer Inst 86: 1234-1238

Richard DE, Berra E, Gothie E, Roux D, Pouyssegur J (1999) p42/p44 mitogen-activated protein kinases phosphorylate hypoxia-inducible factor 1alpha (HIF-1alpha) and enhance the transcriptional activity of HIF-1. I Biol Chem 274: 32631 - 32637

Saito S, Tsuno N, Nagawa H, Sunami E, Zhengxi J, Osada T, Kitayama J, Shibata Y, Tsuruo T, Muto T (2000) Expression of platelet-derived endothelial cell growth factor correlates with good prognosis in patients with colorectal carcinoma. Cancer 88: $42-49$

Shimaoka S, Matsushita S, Nitanda T, Matsuda A, Nioh T, Suenaga T, Nishimata Y, Akiba S, Akiyama S, Nishimata H (2000) The role of thymidine phosphorylase expression in the invasiveness of gastric carcinoma. Cancer 88: 2220-2227

Sivridis E, Giatromanolaki A, Anastasiadis P, Georgiou L, Gatter KC, Harris AL, Bicknell R, Koukourakis MI (2002a) Angiogenic co-operation of VEGF and stromal cell TP in endometrial carcinomas. J Pathol 196: 416-422
Sivridis E, Giatromanolaki A, Gatter KC, Harris AL, Koukourakis MI (2002b) Association of hypoxia-inducible factors 1alpha and 2alpha with activated angiogenic pathways and prognosis in patients with endometrial carcinoma. Cancer 95: 1055-1063

Takahashi Y, Bucana CD, Liu W, Yoneda J, Kitadai Y, Cleary KR, Ellis LM (1996) Platelet-derived endothelial cell growth factor in human colon cancer angiogenesis: role of infiltrating cells. J Natl Cancer Inst 88: $1146-1151$

Takebayashi Y, Miyadera K, Akiyama S, Hokita S, Yamada K, Akiba S, Yamada Y, Sumizawa T, Aikou T (1996) Expression of thymidine phosphorylase in human gastric carcinoma. Jpn J Cancer Res 87: $288-295$

Takebayashi Y, Natsugoe S, Baba M, Akiba S, Fukumoto T, Miyadera K, Yamada Y, Takao S, Akiyama S, Aikou T (1999) Thymidine phosphorylase in human esophageal squamous cell carcinoma. Cancer 85: $282-289$

Tevaearai HT, Laurent PL, Suardet L, Eliason JF, Givel JC, Odartchenko N (1992) Interactions of interferon-alpha 2a with $5^{\prime}$-deoxy-5-fluorouridine in colorectal cancer cells in vitro. Eur J Cancer 28: 368-372

Toi M, Hoshina S, Taniguchi T, Yamamoto Y, Ishitsuka H, Tominaga T (1995a) Expression of platelet-derived endothelial cell growth factor/ thymidine phosphorylase in human breast cancer. Int J Cancer 64: 79-82

Toi M, Inada K, Hoshina S, Suzuki H, Kondo S, Tominaga T (1995b) Vascular endothelial growth factor and platelet-derived endothelial cell growth factor are frequently coexpressed in highly vascularized human breast cancer. Clin Cancer Res 1: 961-964

Tokumo K, Kodama J, Seki N, Nakanishi Y, Miyagi Y, Kamimura S, Yoshinouchi M, Okuda H, Kudo T (1998) Different angiogenic pathways in human cervical cancers. Gynecol Oncol 68: 38-44

Ueda M, Terai Y, Kumagai K, Ueki K, Kanemura M, Ueki M (2001) Correlation between thymidine phosphorylase expression and invasion phenotype in cervical carcinoma cells. Int J Cancer 91: 778-782

Ueda M, Terai Y, Kumagai K, Ueki K, Okamoto Y, Ueki M (1999) Correlation between tumor angiogenesis and expression of thymidine phosphorylase, and patient outcome in uterine cervical carcinoma. Hum Pathol 30: $1389-1394$

van Triest B, Pinedo HM, Blaauwgeers JL, van Diest PJ, Schoenmakers PS, Voorn DA, Smid K, Hoekman K, Hoitsma HF, Peters GJ (2000) Prognostic role of thymidylate synthase, thymidine phosphorylase/ platelet-derived endothelial cell growth factor, and proliferation markers in colorectal cancer. Clin Cancer Res 6: 1063-1072

Wang V, Davis DA, Haque M, Huang LE, Yarchoan R (2005) Differential gene up-regulation by hypoxia-inducible factor-1alpha and hypoxiainducible factor-2alpha in HEK293T cells. Cancer Res 65: 3299-3306

West CM, Davidson SE, Roberts SA, Hunter RD (1993) Intrinsic radiosensitivity and prediction of patient response to radiotherapy for carcinoma of the cervix. Br J Cancer 68: 819-823

Yasuno M, Mori T, Koike M, Takahashi K, Toi M, Takizawa T, Shimizu S, Yamaguchi T, Matsumoto H (2005) Importance of thymidine phosphorylase expression in tumor stroma as a prognostic factor in patients with advanced colorectal carcinoma. Oncol Rep 13: 405-412

Yoshimura A, Kuwazuru Y, Furukawa T, Yoshida H, Yamada K, Akiyama S (1990) Purification and tissue distribution of human thymidine phosphorylase; high expression in lymphocytes, reticulocytes and tumors. Biochim Biophys Acta 1034: 107-113

Zundel W, Schindler C, Haas-Kogan D, Koong A, Kaper F, Chen E, Gottschalk AR, Ryan HE, Johnson RS, Jefferson AB, Stokoe D, Giaccia AJ (2000) Loss of PTEN facilitates HIF-1-mediated gene expression. Genes Dev 14: $391-396$ 